\title{
Crystal Structure and Photophysical Properties of a Novel Dy-Hg Isonicotinic Acid Compound with One-Dimensional Chain-Like Cations
}

\author{
Wen-Tong Chen ${ }^{\star}$ \\ ${ }^{1}$ Institute of Applied Chemistry, School of Chemistry and Chemical Engineering, Jian Key Laboratory of Photoelectric \\ Crystal Materials and Device, Humic Acid Utilization Engineering Research Center of Jiangxi Province, Jiangxi Province \\ Key Laboratory of Coordination Chemistry, Jinggangshan University, 343009, Jian, Jiangxi, China \\ ${ }^{2}$ Department of Ecological and Resources Engineering, Fujian Key Laboratory of Eco-Industrial Green Technology, \\ Wuyi University, Wuyishan, Fujian 354300, China \\ ${ }^{3}$ State Key Laboratory of Structural Chemistry, Fujian Institute of Research on the Structure of Matter, \\ Chinese Academy of Sciences, Fuzhou, Fujian 350002, China \\ *Corresponding author: E-mail: wtchen_2000@aliyun.com \\ Tel \& Fax: Tel.: +86(796)8100490; fax +86(796)8100490
}

Received: 02-17-2020

\begin{abstract}
A novel Dy-Hg compound [Dy $\left.(\mathrm{HIA})_{3}\left(\mathrm{H}_{2} \mathrm{O}\right)_{2}\right]_{2 n} \cdot 2 n \mathrm{HgCl}_{4} \cdot n \mathrm{HgCl}_{5} \cdot n \mathrm{H}_{3} \mathrm{O} \cdot 3 n \mathrm{H}_{2} \mathrm{O}(\mathbf{1} ; \mathrm{HIA}=$ isonicotinic acid $)$ was prepared through a hydrothermal reaction and characterized by X-ray diffraction. The compound crystallizes in the space group of $C 2 / c$ of the monoclinic system. The crystal structure of compound $\mathbf{1}$ has one-dimensional (1-D) chain-like cations. A photoluminescence experiment with a solid-state sample revealed that this compound exhibits a yellow emission band at $575 \mathrm{~nm}$ and, this emission band shall come from the $4 f$ electron ${ }^{4} F_{9 / 2} \rightarrow{ }^{6} H_{13 / 2}$ characteristic transfer of Dy ${ }^{3+}$ ions. The compound features CIE chromaticity coordinates of 0.5168 and 0.4824 in the yellow region. A UV-visible diffuse reflectance spectrum with a solid-state sample unveiled that this compound possesses a wide optical band gap of $3.39 \mathrm{eV}$.
\end{abstract}

Keywords: Chromaticity coordinate; mercury; dysprosium; photoluminescence; lanthanide

\section{Introduction}

It is well-known that most of lanthanide(III) ions (not including $\mathrm{La}^{3+}$ and $\mathrm{Lu}^{3+}$ ions) can usually show fine photoluminescence performances and, in recent years, new lanthanide materials with interesting photoluminescence properties have drawn more and more attention from the researchers in chemical, physical, material and other domains. ${ }^{1-5}$ As of today, a large number of researchers have been devoting themselves to the preparation, structures, physical and chemical characterization of new lanthanide materials, in order to explore their various potential applications in luminescent probes, cell imaging, catalysts, magnetic materials, electrochemical displays, sensors, light-emitting diodes, and so forth.$^{6-12}$ Relative to the large number of investigations on the photoluminescence behavior of new lanthanide materials, only very few investigations on the semiconductor properties of lanthanide materials have been explored so far and, therefore, more studies are still necessary. ${ }^{13}$

Many transition metal-containing compounds generally possess attractive properties that enable them to display potential applications in the areas of chemistry, materials, physics, biology and other fields. As a result, new transition metal-containing materials with novel properties also have attracted more and more interest since many years ago. ${ }^{14-27}$ In recent years, a large amount of effort has been carried out to explore new transition metal-containing materials. ${ }^{28-40}$ As a member of transition metal-containing compounds, group 12 (IIB) metal-containing compounds are also attractive. ${ }^{41-45}$ Moreover, isonicotinic acid is an attractive and important organic molecule, because it can be applied as a useful synthetic ligand. This is due to the fact that it features two carboxyl oxygen chelating atoms at 
one end and one nitrogen atom at the other end. It is known that oxygen atoms are favorable to coordinate to lanthanide metals, while nitrogen atoms are favorable to coordinate to transition metals. So, it is believed that the isonicotinic acid is able to simultaneously bind to lanthanide and transition metals and form an extended motif. Over these years, the investigations on new materials with novel photoluminescence and semiconductor behavior, especially lanthanide-mercury-containing compounds, have become one of my research topics. In present paper, a novel Dy- $\mathrm{Hg}$ material $\quad\left[\mathrm{Dy}(\mathrm{HIA})_{3}\left(\mathrm{H}_{2} \mathrm{O}\right)_{2}\right]_{2 n} \cdot 2 n \mathrm{HgCl}_{4} \cdot n \mathrm{HgCl}_{5} \cdot n \mathrm{H}_{3} \mathrm{O} \cdot 3 n \mathrm{H}_{2} \mathrm{O}$ (1; HIA = isonicotinic acid) is reported with its hydrothermal synthesis, X-ray structure, photophysical behaviors as well as thermogravimetry. This compound is characterized by one-dimensional (1-D) chain-like cations.

\section{Experimental Section}

\section{1. Materials and Characterization}

In this study all of the chemicals applied for the preparation of $\mathbf{1}$ were AR grade purity and commercially available. Elemental microanalyses of carbon, hydrogen and nitrogen were carried out on an Elementar Vario EL elemental analyzer. The FT-IR data set was measured on a PE Spectrum-One FT-IR spectrophotometer with a $\mathrm{KBr}$ pellet. The photoluminescence spectrum was carried out with a solid-state sample of $\mathbf{1}$ on a F97XP spectrometer. The UV-visible diffuse reflectance spectrum was carried out with a solid-state sample of $\mathbf{1}$ on a TU1901 spectrometer. A thermogravimetry (TG) diagram was measured on a NETZSCH TG 209F3 TG analyzer under nitrogen atmosphere.

\section{2. Synthesis of $\left[\mathrm{Dy}(\mathrm{HIA})_{3}\left(\mathrm{H}_{2} \mathrm{O}\right)_{2}\right]_{2 \mathrm{n}}$. $2 \mathrm{nHgCl}_{4} \cdot \mathbf{n H g C l}_{5} \cdot \mathbf{n H}_{3} \mathrm{O} \cdot \mathbf{3} \mathbf{n H}_{\mathbf{2}} \mathrm{O}(1)$}

A mixture of $3.5 \mathrm{mmol} \mathrm{HgCl}_{2}(952 \mathrm{mg}), 3 \mathrm{mmol}$ isonicotinic acid $(369 \mathrm{mg}), 1 \mathrm{mmol} \mathrm{DyCl}{ }_{3} \cdot 6 \mathrm{H}_{2} \mathrm{O}(377 \mathrm{mg})$ and $10 \mathrm{~mL}$ distilled water was added into a $25 \mathrm{~mL}$ Teflon-lined stainless steel vessel and the vessel was heated at $433 \mathrm{~K}$ for two weeks under autogenous pressure, then powered off. Colorless block crystals can be found when the vessel temperature was cooled down. The yield was $33 \%$ calculated on $\mathrm{HgCl}_{2}$. Anal. Calcd. For $\mathrm{C}_{36} \mathrm{H}_{47} \mathrm{Cl}_{13}$ Dy${ }_{2} \mathrm{Hg}_{3} \mathrm{~N}_{6} \mathrm{O}_{20}$ : C, 19.04; H, 2.09; N, 3.70. Found: C, 19.11; H, 2.12; N, 3.75. FTIR peaks $\left(\mathrm{cm}^{-1}\right)$ : 3450(vs), 3143(w), 3072(m), 2889(w), 1691(m), 1592(vs), 1410(vs), 1233(m), 1077(w), 1050(w), 999(w), 848(m), 759(s), 681(s), 540(m) and $410(\mathrm{~m})$.

\section{3. Crystal Structure Determination and Refinement}

A carefully selected single crystal with dimensions $0.10 \mathrm{~mm} \times 0.07 \mathrm{~mm} \times 0.04 \mathrm{~mm}$ was adhered on the top of a glass fiber, then mounted to a SuperNova CCD diffractometer with the X-ray source being of a graphite monochromatic Mo-K $\alpha$ radiation $(\lambda=0.71073 \AA)$. The $\mathrm{X}$-ray intensity data set was measured with an $\omega$ scan mode. The CrystalClear software was used for data reduction and absorption correction. The single crystal molecular structure of the title compound was solved by means of the direct methods and the structure was finally refined on $F^{2}$ with full-matrix least-squares and the Siemens SHELXTL ${ }^{\mathrm{TM}}$ V5 program. All of the non-hydrogen atoms were set on their difference Fourier peaks and anisotropically refined. Hydrogen atoms were theoretically generated, except for several on water molecules were generated on difference Fourier peaks. Hydrogen atoms at $\mathrm{O} 1 \mathrm{~W}$ and $\mathrm{O} 4 \mathrm{~W}$ were not found. Some bad equivalents were cut off in order to obtain more reasonable structure. 14 distance or angle restraints were used, in order to get more accurate results. Important crystal data and refinement details are depicted in Table 1 and some important bond lengths and angles are shown in Table 2.

Table 1. Crystal data of 1.

\begin{tabular}{ll}
\hline Formula & $\mathrm{C}_{36} \mathrm{H}_{47} \mathrm{Cl}_{13} \mathrm{Dy}_{2} \mathrm{Hg}_{3} \mathrm{~N}_{6} \mathrm{O}_{20}$ \\
$M_{\mathrm{r}}$ & 2271.42 \\
color & colorless \\
Crystal system & monoclinic \\
Space group & $C 2 / c$ \\
$a(\AA)$ & $24.2350(4)$ \\
$b(\AA)$ & $20.8170(4)$ \\
$c(\AA)$ & $15.3597(2)$ \\
$\beta\left({ }^{\circ}\right)$ & $127.925(2)$ \\
$V\left(\AA^{3}\right)$ & $6112.51(17)$ \\
$Z$ & 4 \\
Reflections collected & 16912 \\
Independent, observed & $5296,4646(0.0196)$ \\
reflections $\left(R_{\text {int }}\right)$ & \\
$d_{\text {calcd. }}\left(\mathrm{g} / \mathrm{cm}{ }^{3}\right)$ & 2.468 \\
$\left.\mu(\mathrm{mm})^{-1}\right)$ & 10.564 \\
$F(000)$ & 4232 \\
$T(\mathrm{~K})$ & $293(2)$ \\
$R^{1}, w R^{2}$ & $0.0330,0.0848$ \\
$S$ & 1.053 \\
Largest and Mean $\Delta / \sigma$ & $0.001,0$ \\
$\Delta \rho(\mathrm{max}$, min $)\left(\mathrm{e} / \AA^{3}\right)$ & $3.145,-1.346$ \\
\hline
\end{tabular}

Table 2. Some bond lengths $(\AA)$ and angles $\left({ }^{\circ}\right)$

\begin{tabular}{lllr}
\hline $\mathrm{Hg} 1-\mathrm{Cl} 1$ & $2.474(5)$ & $\mathrm{Cl} 4-\mathrm{Hg} 2-\mathrm{Cl} 7$ & $105.78(7)$ \\
$\mathrm{Hg} 1-\mathrm{Cl} 2$ & $2.463(4)$ & $\mathrm{O} 4 \# 2-\mathrm{Dy} 1-\mathrm{O} 1$ & $145.78(17)$ \\
$\mathrm{Hg} 1-\mathrm{Cl} 3$ & $2.262(4)$ & $\mathrm{O} 4 \# 2-\mathrm{D} 1-\mathrm{O} 2 \# 3$ & $78.05(16)$ \\
$\mathrm{Hg} 1-\mathrm{Cl} 3 \# 1$ & $2.633(3)$ & $\mathrm{O} 1-\mathrm{D} 1-\mathrm{O} 2 \# 3$ & $76.60(16)$ \\
$\mathrm{Hg} 1-\mathrm{Hg} 1 \# 1$ & $1.2373(14)$ & $\mathrm{O} 4 \# 2-\mathrm{Dy} 1-\mathrm{O} 3$ & $103.56(15)$ \\
$\mathrm{Hg} 2-\mathrm{Cl} 4$ & $2.477(2)$ & $\mathrm{O} 1-\mathrm{Dy} 1-\mathrm{O} 3$ & $81.75(16)$ \\
$\mathrm{Hg} 2-\mathrm{Cl} 5$ & $2.4502(19)$ & $\mathrm{O} 2 \# 3-\mathrm{Dy} 1-\mathrm{O} 3$ & $139.23(16)$
\end{tabular}




\begin{tabular}{lllr} 
Hg2-Cl6 & $2.4628(19)$ & O4\#2-Dy1-O6\#3 & $138.03(16)$ \\
Hg2-Cl7 & $2.5641(17)$ & O1-Dy1-O6\#3 & $76.09(16)$ \\
Dy1-O1 & $2.382(4)$ & O2\#3-Dy1-O6\#3 & $126.09(16)$ \\
Dy1-O4\#2 & $2.378(4)$ & O3-Dy1-O6\#3 & $80.04(16)$ \\
Dy1-O3 & $2.404(4)$ & O4\#2-Dy1-O5 & $80.99(16)$ \\
Dy1-O2\#3 & $2.384(4)$ & O1-Dy1-O5 & $113.47(16)$ \\
Dy1-O5 & $2.421(4)$ & O2\#3-Dy1-O5 & $74.59(16)$ \\
Dy1-O6\#3 & $2.411(4)$ & O3-Dy1-O5 & $146.17(17)$ \\
Dy1-O1W & $2.529(4)$ & O6\#3-Dy1-O5 & $75.16(16)$ \\
Dy1-O2W & $2.489(5)$ & O4\#2-Dy1-O2W & $71.39(15)$ \\
& & O1-Dy1-O2W & $140.56(16)$ \\
Cl3-Hg1-Cl2 & $108.81(13)$ & O2\#3-Dy1-O2W & $140.46(16)$ \\
Cl3-Hg1-Cl1 & $122.95(9)$ & O3-Dy1-O2W & $73.66(16)$ \\
Cl2-Hg1-Cl1 & $91.49(10)$ & O6\#3-Dy1-O2W & $69.72(15)$ \\
Cl3-Hg1-Cl3\#1 & $111.45(15)$ & O5-Dy1-O2W & $76.34(16)$ \\
Cl2-Hg1-Cl3\#1 & $111.13(13)$ & O4\#2-Dy1-O1W & $77.38(15)$ \\
Cl1-Hg1-Cl3\#1 & $109.15(8)$ & O1-Dy1-O1W & $72.50(15)$ \\
Cl5-Hg2-Cl6 & $117.08(7)$ & O2\#3-Dy1-O1W & $69.72(14)$ \\
Cl5-Hg2-Cl4 & $113.82(7)$ & O3-Dy1-O1W & $70.99(15)$ \\
Cl6-Hg2-Cl4 & $109.83(7)$ & O6\#3-Dy1-O1W & $139.63(15)$ \\
Cl5-Hg2-Cl7 & $104.21(6)$ & O5-Dy1-O1W & $141.24(15)$ \\
Cl6-Hg2-Cl7 & $104.91(6)$ & O2W-Dy1-O1W & $124.81(15)$ \\
\hline
\end{tabular}

Symmetry codes: $\# 1-x+1, y,-z+5 / 2 ; \# 2-x+1 / 2,-y+1 / 2,-z+1$; $\# 3-x+1, y,-z+3 / 2$

Table 3. Hydrogen bonding interactions

\begin{tabular}{|c|c|c|c|c|}
\hline $\mathrm{D}-\mathrm{H} \cdots \mathrm{A}$ & $\mathrm{D}-\mathrm{H}, \AA$ & $\mathrm{H} \cdots \mathrm{A}, \AA$ & $\mathrm{D} \cdots \mathrm{A}, \AA$ & $\mathrm{D}-\mathrm{H} \cdots \mathrm{A},{ }^{\circ}$ \\
\hline N1-H1B $\cdots C l 7 \# 1$ & 0.86 & 2.36 & $3.151(10)$ & 154 \\
\hline $\mathrm{N} 2-\mathrm{H} 2 \mathrm{~B} \cdots \mathrm{Cl} 4 \# 2$ & 0.86 & 2.58 & $3.298(8)$ & 141 \\
\hline N3-H3A…O4W\#3 & 0.86 & 2.00 & $2.827(14)$ & 162 \\
\hline O3W-H3WA …Cl4\#3 & $0.85(11)$ & $2.41(13)$ & $3.211(11)$ & $157(15)$ \\
\hline $\mathrm{O} 3 \mathrm{~W}-\mathrm{H} 3 \mathrm{WB} \cdots \mathrm{Cl} 5$ & $0.86(11)$ & $2.39(14)$ & $3.215(10)$ & $161(17)$ \\
\hline $\mathrm{O} 2 \mathrm{~W}-\mathrm{H} 2 \mathrm{WB} \cdots \mathrm{Cl} 6$ & $0.85(7)$ & $2.37(7)$ & $3.199(5)$ & $166(8)$ \\
\hline C7-H7A $\cdots \mathrm{Cl} 2 \# 5$ & 0.93 & 2.57 & $3.395(11)$ & 148 \\
\hline
\end{tabular}

Symmetry codes: $\# 1: 1 / 2+x,-1 / 2+y, z ; \# 2: x, 1-y,-1 / 2+z ; \# 3 x, 1-y$,

$1 / 2+z ; \# 4 \frac{1 / 2}{1 / 2} x, 1 / 2-y, 1-z ; \# 5-1 / 2+x, 1 / 2-y,-3 / 2+z$.

\section{Results and Discussion}

The FT-IR spectrum exhibits that the bands of compound $\mathbf{1}$ are mainly in the frequency range of 410-1691 $\mathrm{cm}^{-1}$. A very strong band at $3450 \mathrm{~cm}^{-1}$ can be ascribed to the $v_{\mathrm{O}-\mathrm{H}}$ stretching vibration mode of the coordinating water. The middle intense peak at $3072 \mathrm{~cm}^{-1}$ should be ascribed to the $v_{\mathrm{C}-\mathrm{H}}$ stretching vibration mode of the pyridyl ring of the isonicotinic acid ligand. The very strong bands at 1592 and $1410 \mathrm{~cm}^{-1}$ can be ascribed to the $v_{\mathrm{C}-\mathrm{O}}$ stretching vibration mode of the coordinating carboxylic moieties and, this means that all carboxylic moieties are coordinated to the metal. The strong peak at $759 \mathrm{~cm}^{-1}$ should be ascribed to the $v_{\mathrm{C}-\mathrm{H}}$ bending vibration mode of the pyridyl rings.

As analyzed by $\mathrm{X}$-ray single crystal diffraction, compound 1 crystallizes in the monoclinic system $C 2 / c$ space group. As depicted in Fig. 1, the asymmetric molecular structure includes crystallographically independent $\mathrm{Hg} 1$ (in the $C 2$ axis with 0.5 occupancies), $\mathrm{Hg} 2, \mathrm{Dy} 1, \mathrm{Cl} 1$ (in the $\mathrm{C} 2$ axis with 0.5 occupancies), $\mathrm{Cl} 2$ to $\mathrm{Cl} 7$, three isonicotinic acid ligands, two coordinating water and two lattice water molecules. So, most of the atoms reside at a general position, but $\mathrm{Hg} 1$ (in 0.5 occupancies) as well as $\mathrm{Cl} 1$ (in 0.5 occupancies) locate at a special position.

The ion $\mathrm{Hg} 1$ is bound by five chloride ions and forms a distorted $\mathrm{HgCl}_{5}$ triangular bipyramidal coordination geometry with the bond angle $\mathrm{Cl}-\mathrm{Hg} 1-\mathrm{Cl}$ in the range of 91.49(10)-122.95(9) ${ }^{\circ}$ and the bond distance $\mathrm{Hg} 1-\mathrm{Cl}$ in the span of 2.262(4)-2.633(3) $\AA$. The ion $\mathrm{Hg} 2$ is bound by four chloride ions and forms a distorted $\mathrm{HgCl}_{4}$ tetrahedron with the bond angle $\mathrm{Cl}-\mathrm{Hg} 2-\mathrm{Cl}$ in the range of 104.21(6)$117.08(7)^{\circ}$ and the bond distance $\mathrm{Hg} 2-\mathrm{Cl}$ in the span of 2.4502(19)-2.5641(17) $\AA$. The bond distances of $\mathrm{Hg}-\mathrm{Cl}$ are comparable with that previously reported in the references. ${ }^{46,47}$ The dysprosium ion Dy1 is surrounded by eight oxygen atoms of which two are water oxygen atoms and six are isonicotinic acid oxygen atoms. The bond distances of Dy-O are in the span of 2.378(4)-2.529(4) $\AA$ with a mean value of 2.424(5) $\AA$ that is also in the normal region. ${ }^{48}$ The bond angles of $\mathrm{O}-\mathrm{Dy}-\mathrm{O}$ are in the range of 69.72(14)$146.17(17)^{\circ}$. The neighbouring $\mathrm{DyO}_{8}$ polyhedra connect to each other through two or four isonicotinic acid moieties to give a one-dimensional (1-D) Dy-(HIA) ${ }_{2}$ - Dy(HIA) ${ }_{4}$-Dy-(HIA) $)_{2}$-Dy-(HIA) ${ }_{4}$-Dy- chain running along the $a$-axis, as shown in Fig. 2. In the title compound, there are many hydrogen bonding interactions, i.e. $\mathrm{N}-\mathrm{H} \cdots \mathrm{Cl}$, $\mathrm{N}-\mathrm{H} \cdots \mathrm{O}, \mathrm{O}-\mathrm{H} \cdots \mathrm{O}, \mathrm{O}-\mathrm{H} \cdots \mathrm{Cl}$ and $\mathrm{C}-\mathrm{H} \cdots \mathrm{Cl}$ (see Table 3, please). These hydrogen bonding interactions link the [Dy $\left.(\mathrm{HIA})_{3}\left(\mathrm{H}_{2} \mathrm{O}\right)_{2}\right]_{2 n}{ }^{6+}$ chains, $\mathrm{HgCl}_{4}{ }^{2-}$ ions, $\mathrm{HgCl}_{5}{ }^{3-}$ ions, and lattice water molecules together to complete a three-dimensional (3-D) supramolecular network, as shown in Fig. 3.

Up to date, some similar compounds have been reported by our group. ${ }^{49-53}$ These compounds are prepared under similar conditions. They have different lanthanides

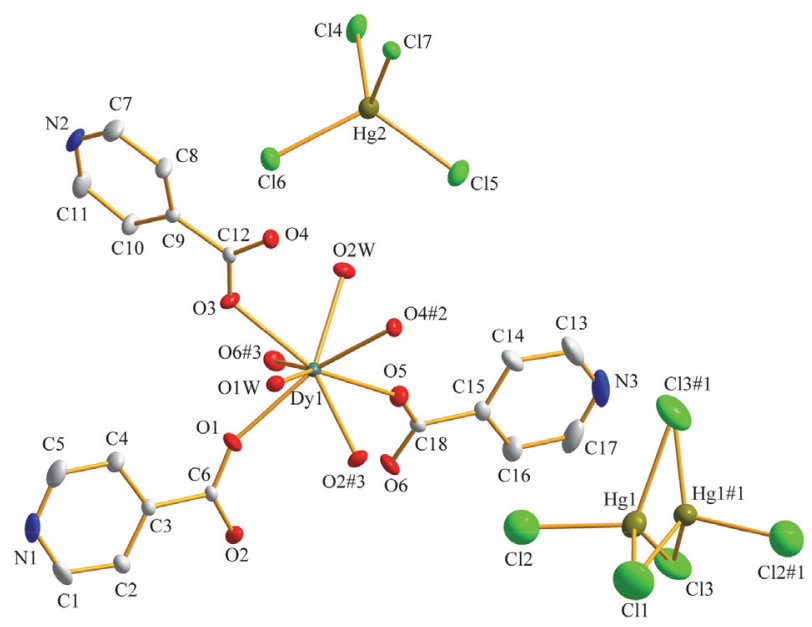

Figure 1. An ORTEP figure of compound $\mathbf{1}$ at $30 \%$ thermal ellipsoids. The lattice water molecules and $\mathrm{H}$ atoms have been omitted for clarity. 
with nicotinic acid or isonicotinic acid as ligands. All of these compounds show one-dimensional (1-D) chain-like cations.

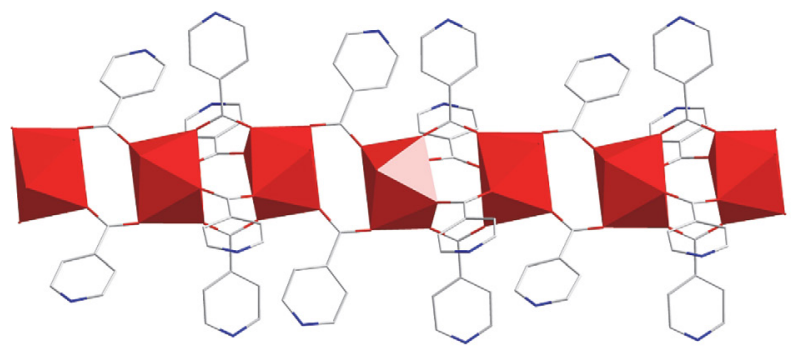

Figure 2. A 1-D chain running along the $a$-axis with the polyhedra representing the $\mathrm{DyO}_{8}$ moieties

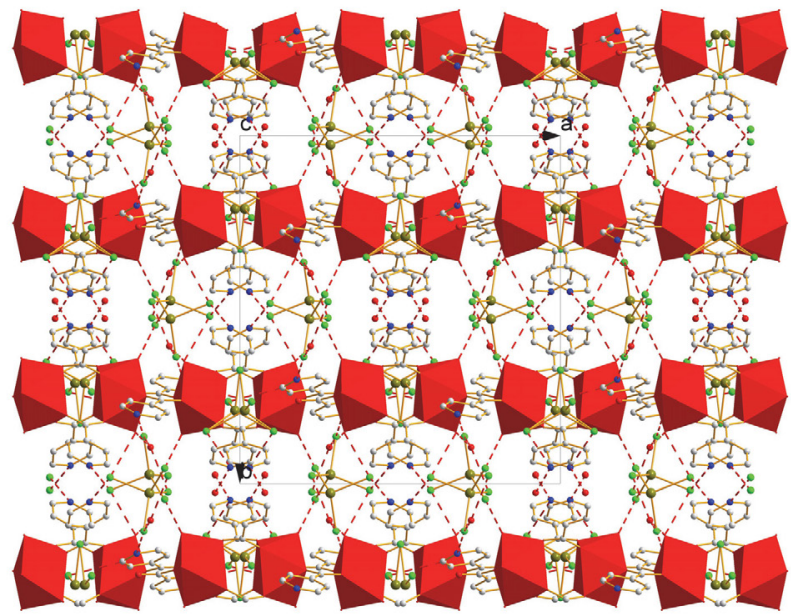

Figure 3. A packing view of $\mathbf{1}$ with the polyhedra representing the $\mathrm{DyO}_{8}$ moieties. The dashed lines are hydrogen bonding interactions (see Table 3, please).

It is known that mercury compounds and dysprosium compounds can generally show photoluminescence performances. As a result, the photoluminescence behavior of the title compound was measured with solid state samples under room temperature. As given in Fig. 4, the photoluminescence adsorption of the title compound locates in the span of 530-560 nm and the maximum peak resides at $547 \mathrm{~nm}$. When the title compound was excited by the $547 \mathrm{~nm}$ wavelength, it exhibits one photoluminescence emission peak that locates at $575 \mathrm{~nm}$ (in yellow region). This emission band shall be attributed to the $4 f$ electrons ${ }^{4} F_{9 / 2} \rightarrow{ }^{6} H_{13 / 2}$ characteristic transfer of the $\mathrm{Dy}^{3+}$ ions. ${ }^{64}$ With regard to compound $\mathbf{1}$, it features CIE chromaticity coordinates of 0.5168 and 0.4824 in the yellow region, as shown in Fig. 5. As a result, compound 1 may be a potential yellow photoluminescence emitting material. Some similar compounds ${ }^{49-53}$ reported by our group show different luminescence properties, because they have different lanthanide ions, such as gadolinium, neodymium, erbium, lanthanum and praseodymium.

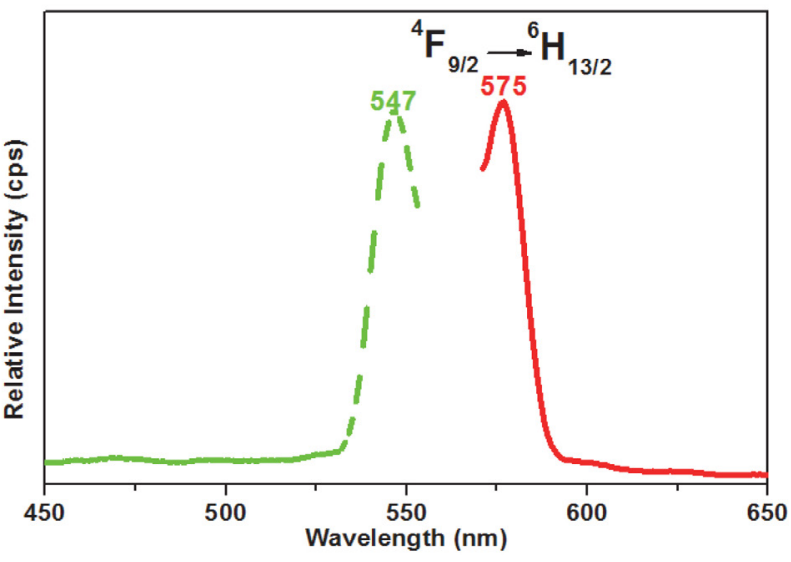

Figure 4. The solid state photoluminescence spectra of 1 measured at room temperature. Green dashed lines represent excitation and red solid lines represent emission.

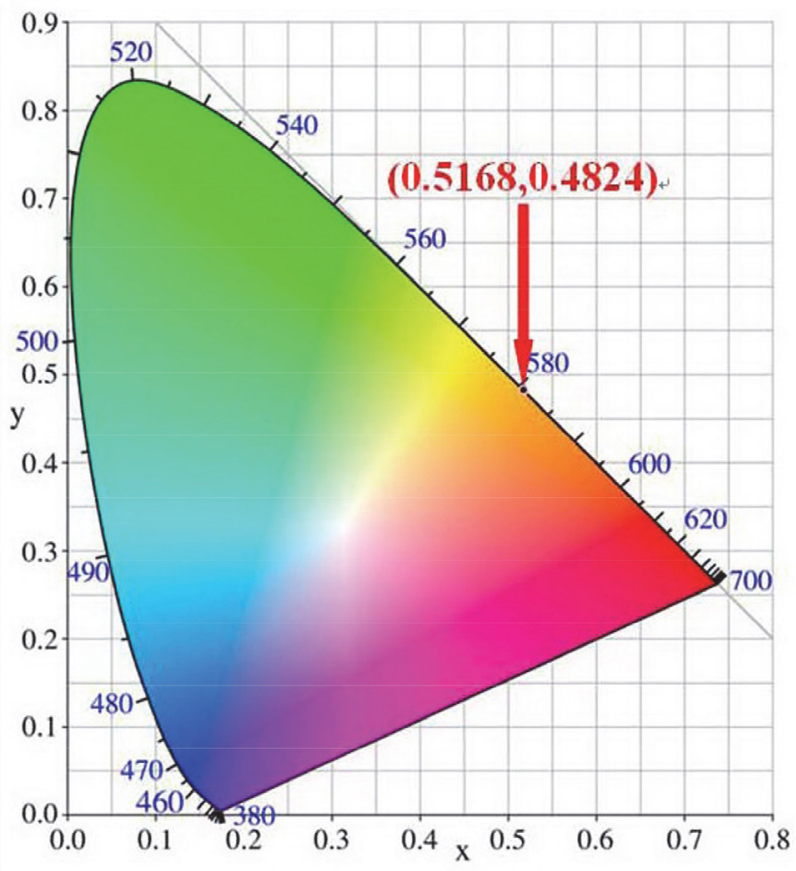

Figure 5. A CIE figure of compound 1.

In general, dysprosium compounds and mercury compounds can exhibit semiconductive behaviors. The title compound consists of both dysprosium and mercury elements; therefore, it can probably show semiconductive properties. For the sake of further studying the photophysical behaviors of compound $\mathbf{1}$, its solid state UV-visible diffuse reflectance spectrum was measured at room temperature with powder samples. Its solid state UV-visible diffuse reflectance spectrum data set was converted with the Kubelka-Munk formula $\alpha / S=(1-R)^{2} / 2 R$ that is commonly used for related researches. With regard to the Kubelka-Munk formula, the $\alpha, S$ and $R$ indicate the absorption coefficient, scattering coefficient and the reflec- 
tion rate, respectively. By means of the linear epitaxy of the maximum absorption edge on the $\alpha / S$ versus energy diagram of compound $\mathbf{1}$, the semiconductor band gap value can be ascertained. As a result, with the use of this method, the semiconductor band gap value of compound $\mathbf{1}$ can be found to be $3.39 \mathrm{eV}$ that is shown in Fig. 6. On the $\alpha / S$ versus energy curve, several small bands between $2.5 \mathrm{eV}$ and $3.3 \mathrm{eV}$ can be found and they shall be attributed to the Dy(III) ions. Based on this band gap value of $3.39 \mathrm{eV}$, it is believed that compound $\mathbf{1}$ may be a wide optical band gap semiconductor material. The maximum absorption edge of the curve is steep, which means that it should undergo a direct transition in the title compound. ${ }^{55}$

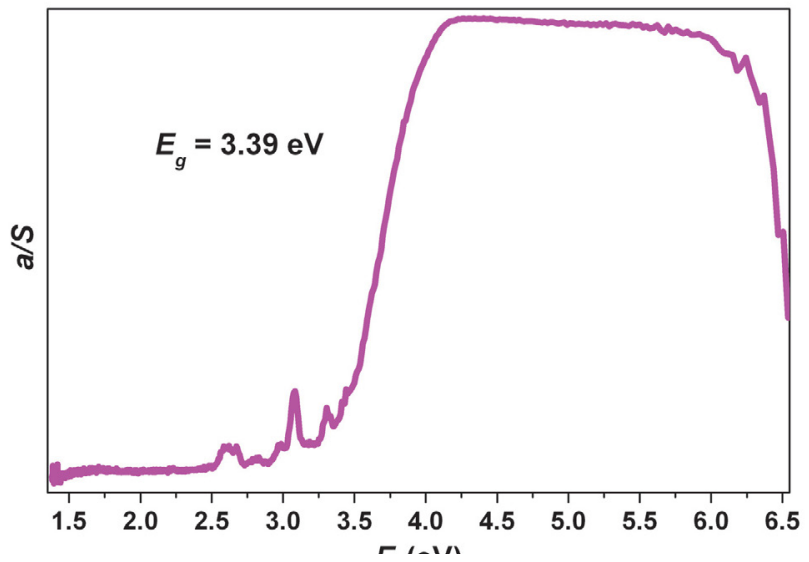

Figure 6. A solid-state diffuse reflectance spectrum of $\mathbf{1}$.

The thermogravimetry (TG) diagram of compound 1 was measured under nitrogen atmosphere. Complex 1 shows a four-step decomposition process with the mass loss being of $3.19 \%, 32.87 \%, 31.88 \%$ and $13.15 \%$, respectively, as depicted in Fig. 7. The total mass loss of compound 1 is $81.09 \%$. At the first stage (until $90.1{ }^{\circ} \mathrm{C}$ ), the mass loss is $3.19 \%$ of the total mass loss; this is due to the

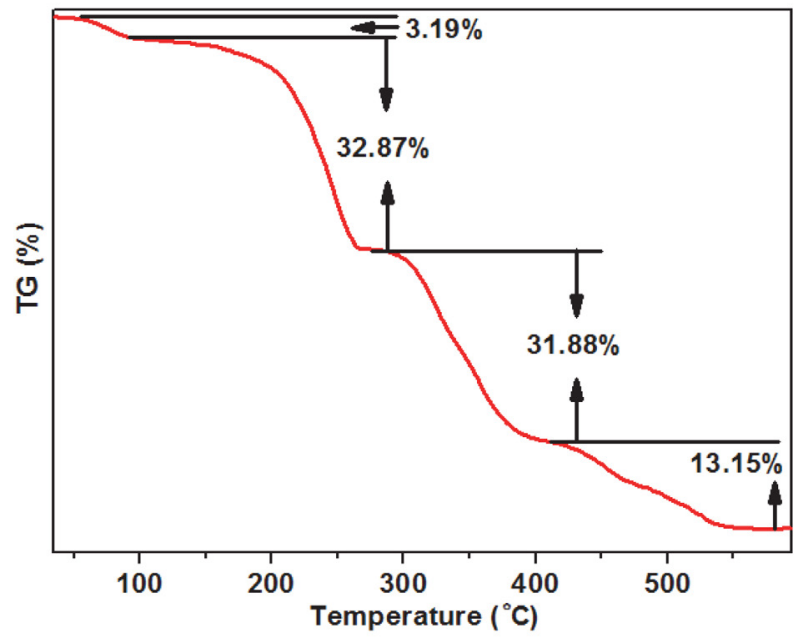

Figure 7. A TG diagram of $\mathbf{1}$. leave of all lattice water molecules (calculated 3.21\%). From $90.1{ }^{\circ} \mathrm{C}$ to $262.9^{\circ} \mathrm{C}$ is the second stage and, at this stage, the mass loss is $32.87 \%$ that can be assigned to the leave of all coordination water molecules and $\mathrm{HgCl}_{4}$ moieties (calculated $33.32 \%$ ). At the third stage (from $262.9^{\circ} \mathrm{C}$ to $421.6^{\circ} \mathrm{C}$ ), the mass loss is $31.88 \%$ which is probably because of the loss of all isonicotinic acid ligands (calculated $32.49 \%$ ). The last step is from $421.6^{\circ} \mathrm{C}$ to $600{ }^{\circ} \mathrm{C}$ and, at this stage, the weight loss is $13.15 \%$ that is because of the loss of some $\mathrm{HgCl}_{5}$ moieties (calculated 16.64\%).

\section{Conclusions}

A novel Dy-Hg compound was hydrothermally prepared and the crystal structure was characterized. The crystal structure has one-dimensional chain-like cations. This compound exhibits a yellow photoluminescence emission peak and this emission peak shall come from the $4 f$ electrons ${ }^{4} F_{9 / 2} \rightarrow{ }^{6} H_{13 / 2}$ characteristic transfer of $\mathrm{Dy}^{3+}$ ions. The compound is characteristic of a CIE chromaticity coordinate of $(0.5168,0.4824)$ in the yellow region. A UV-visible diffuse reflectance spectrum measured with a solid-state sample unveiled that the compound possesses a wide optical band gap of $3.39 \mathrm{eV}$. Therefore, the compound may be a candidate of yellow photoluminescence emission materials and wide optical band gap semiconductor materials.

\section{Acknowledgments}

The present work is supported by the open foundation of the State Key Laboratory of Structural Chemistry, Fujian Institute of Research on the Structure of Matter, Chinese Academy of Sciences (20180008).

\section{Supplementary Material}

Crystallographic data for the structural analysis has been deposited with the Cambridge Crystallographic Data Centre, CCDC No. 1983374. Copies of this information may be obtained free of charge from the Director, CCDC, 12 Union Road, Cambridge, CBZ 1EZ, UK (Fax: +441223-336033; email: deposit@ccdc.cam.ac.uk or www: http://www.ccdc. cam.ac.uk).

\section{References}

1. G. X. Wen, M. L. Han, X. Q. Wu, Y. P. Wu, W. W. Dong, J. Zhao, D. S. Li, L. F. Ma, Dalton Trans. 2016, 45, 15492-15499. DOI:10.1039/C6DT03057B

2. A. E. Sedykh, D. G. Kurth, K. Mueller-Buschbaum, Eur. J. Inorg. Chem. 2019, 42, 4564-4571.

DOI:10.1002/ejic.201900872 
3. S.-J. Liu, C. Cao, C.-C. Xie, T.-F. Zheng, X.-L. Tong, J.-S. Liao, J.-L. Chen, H.-R. Wen, Z. Chang, X.-H. Bu, Dalton Trans. 2016, 45, 9209-9215. DOI:10.1039/C6DT01349J

4. K. Burek, J. Dengler, F. Emmerling, I. Feldmann, M. U. Kumke, J. Stroh, ChemistryOpen 2019, 8, 1441-1452.

DOI:10.1002/open.201900249

5. Z. Zhou, J. P. Gu, X. G. Qiao, H. X. Wu, H. R. Fu, L. Wang, H. Y. Li, L. F. Ma, Sensor. Actuat. B-Chem. 2019, 282, 437-442. DOI:10.1016/j.snb.2018.11.103

6. X. H. Xiong, Y. Tao, Z. W. Yu, L. X. Yang, L. J. Sun, Y. L. Fan, F. Luo, Chem. Engin. J. DOI:10.1016/j.cej.2019.123240.

7. F. Oukhatar, S. V. Eliseeva, C. S. Bonnet, M. Placidi, N. K. Logothetis, S. Petoud, G. Angelovski, E. Toth, Inorg. Chem. 2019, 58, 13619-13630.

DOI:10.1021/acs.inorgchem.9b00887

8. S.-J. Liu, C. Cao, S.-L. Yao, T.-F. Zheng, Z.-X. Wang, C. Liu, J.-S. Liao, J.-L. Chen, Y.-W. Li, H.-R. Wen, Dalton Trans. 2017, 46, 64-70. DOI:10.1039/C6DT03589B

9. X. Yao, G. H. An, Y. X. Li, P. F. Yan, W. Z. Li, G. M. Li, J. Solid State Chem. 2019, 274, 295-302.

DOI:10.1016/j.jssc.2019.03.044

10. J.-H. Wei, J.-W. Yi, M.-L. Han, B. Li, S. Liu, Y.-P. Wu, L.-F. Ma, D.-S. Li, Chem.- Asian J. 2019, 14, 3694-3701.

DOI:10.1002/asia.201900706

11. W.-S. Lin, W.-T. Chen, H.-M. Kuang, H. Luo, Acta Chim. Slov. 2018, 65, 1008-1013. DOI:10.17344/acsi.2017.4833

12. H. Khajuria, M. Kumar, L. Tashi, R. Singh, H. N. Sheikh, Acta Chim. Slov. 2020, 67, 119-129. DOI:10.17344/acsi.2019.5274

13. Y. Hasegawa, T. Kawai, CSJ Curr. Rev. 2012, 9, 139-144.

14. H. Q. Wu, C. S. Yan, F. Luo, R. Krishna, Inorg. Chem. 2018, 57, 3679-3682. DOI:10.1021/acs.inorgchem.8b00341

15. S. A. Yaseen, A. S. Alameen, F. A. Saif, S. B. Undre, P. W. Khirade, P. B. Undre, Integr. Ferroelectr. 2020, 205, 131-145. DOI:10.1080/10584587.2019.1675009

16. Y. Zhao, Z. M. Zhai, X. Y. Liu, X. G. Yang, L. F. Ma, L. Y. Wang, J. Solid State Chem. 2019, 278, 120913.

DOI:10.1016/j.jssc.2019.120913

17. K. Nishio, N. Nakamura, K. Horiba, M. Kitamura, H. Kumigashira, R. Shimizu, T. Hitosugi, Appl. Phys. Lett. 2020, 116, 053901/1-053901/5. DOI:10.1063/1.5133879

18. J. Q. Li, L. L. Gong, X. F. Feng, L. Zhang, H. Q. Wu, C. S. Yan, Y. Y. Xiong, H. Y. Gao, F. Luo, Chem. Eng. J. 2017, 316, 154159. DOI:10.1016/j.cej.2017.01.046

19. X. X. Wu, H. R. Fu, M. L. Han, Z. Zhou, L. F. Ma, Cryst. Growth Des. 2017, 17, 6041-6048.

DOI:10.1021/acs.cgd.7b01155

20. C. B. Fan, L. L. Gong, L. Huang, F. Luo, R. Krishna, X. F. Yi, A. M. Zheng, L. Zhang, S. Z. Pu, X. F. Feng, M. B. Luo, G. C. Guo, Angew. Chem. Int. Ed. 2017, 56, 7900-7906.

DOI:10.1002/anie.201702484

21. Z. T. Omar, S. Jadhav, M. Rai, Integr. Ferroelectr. 2020, 205, 88-94. DOI:10.1080/10584587.2019.1675003

22. Y. P. Wu, J. W. Tian, S. Liu, B. Li, J. Zhao, L. F. Ma, D. S. Li, Y. Q. Lan, X. Bu, Angew. Chem. Int. Ed. 2019, 58, 12185-12189. DOI:10.1002/anie.201907136

23. L. L. Gong, X. F. Feng, F. Luo, X. F. Yi, A. M. Zheng, Green
Chem. 2016, 18, 2047-2055. DOI:10.1039/C5GC02182K

24. Z. Li, A. Yang, X. Ma, Z. Liu, J. Chem. Res. 2020, 44, 97-103. DOI:10.1177/1747519819880693

25. Y. J. Cheng, R. Wang, S. Wang, X. J. Xi, L. F. Ma, S. Q. Zang, Chem. Commun. 2018, 54, 13563-13566.

DOI:10.1039/C8CC07784C

26. W. H. Yin, Y. Y. Xiong, H. Q. Wu, Y. Tao, L. X. Yang, J. Q. Li, X. L. Tong, F. Luo, Inorg. Chem. 2018, 57, 8722-8725.

DOI:10.1021/acs.inorgchem.8b01457

27. X.-N. Fang, J. Li, X.-G. Yi, Q. Luo, J.-Y. Chen, Y.-X. Li, Acta Chim. Slov. 2019, 66, 414-420. DOI:10.17344/acsi.2018.4885

28. Z. M. Zhai, X. G. Yang, Z. T. Yang, X. M. Lu, L. F. Ma, CrystEngComm 2019, 21, 5862-5866. DOI:10.1039/C9CE00944B

29. P. Heiss, J. Hornung, X. Zhou, C. Jandl, A. Poethig, C. Gemel, R. A. Fischer, Inorg. Chem. 2020, 59, 514-522.

DOI:10.1021/acs.inorgchem.9b02798

30. H. Wang, W. Meng, J. Wu, J. Ding, H. Hou, Y. Fan, Coor. Chem. Rev. 2016, 307, 130-146.

DOI:10.1016/j.ccr.2015.05.009

31. H. R. Fu, Y. Zhao, Z. Zhou, X. G. Yang, L. F. Ma, Dalton Trans. 2018, 47, 3725-3732. DOI:10.1039/C8DT00206A

32. X. G. Yang, Z. M. Zhai, X. M. Lu, Y. Zhao, X. H. Chang, L. F. Ma, Dalton Trans. 2019, 48, 10785-10789.

DOI:10.1039/C9DT02178G

33. M. B. Luo, Y. Y. Xiong, H. Q. Wu, X. F. Feng, J. Q. Li, F. Luo, Angew. Chem. Int. Ed. 2017, 56, 16376-16379.

DOI:10.1002/anie.201709197

34. B. Samannan, J. Selvam, J. Thavasikani, Asian J. Chem. 2020, 32, 297-302. DOI:10.14233/ajchem.2020.22321

35. Y. Zhao, D. S. Deng, L. F. Ma, B. M. Ji, L. Y. Wang, Chem. Commun. 2013, 49, 10299-10301. DOI:10.1039/c3cc45310c

36. W. R. Osterloh, G. Galindo, M. J. Yates, E. Van Caemelbecke, K. M. Kadish, Inorg. Chem. 2020, 59, 584-594.

DOI:10.1021/acs.inorgchem.9b02838

37. X. G. Yang, L. F. Ma, D. P. Yan, Chem. Sci. 2019, 10, 45674572. DOI:10.1039/C9SC00162J

38. H. R. Fu, N. Wang, J. H. Qin, M. L. Han, L. F. Ma, F. Wang, Chem. Commun. 2018, 54, 11645-11648.

DOI:10.1039/C8CC05990J

39. K. Anuja, K. H. Reddy, K. Srinivasulu, D. Dhanalakshmi, Asian J. Chem. 2020, 32, 322-328.

DOI:10.14233/ajchem.2020.22389

40. Y. Zhao, L. Wang, N. N. Fan, M. L. Han, G. P. Yang, L. F. Ma, Cryst. Growth Des. 2018, 18, 7114-7121.

DOI:10.1021/acs.cgd.8b01290

41. Y. Zhao, X. G. Yang, X. M. Lu, C. D. Yang, N. N. Fan, Z. T. Yang, L. Y. Wang, L. F. Ma, Inorg. Chem. 2019, 58, 6215-6221. DOI:10.1021/acs.inorgchem.9b00450

42. N. Ahmad, S. Sultana, S. M. Faisal, A. Ahmed, S. Sabir, M. Z. Khan, RSC Adv. 2019, 9, 41135-41150.

DOI:10.1039/C9RA06493A

43. Z. Zhou, M. L. Han, H. R. Fu, L. F. Ma, F. Luo, D. S. Li, Dalton Trans. 2018, 47, 5359-5365. DOI:10.1039/C8DT00594J

44. D. Bouokkeze, J. Massoudi, W. Hzez, M. Smari, A. Bougoffa, K. Khirouni, E. Dhahri, L. Bessais, RSC Adv. 2019, 9, 4094040955. DOI:10.1039/C9RA07569K 
45. J. H. Qin, Y. D. Huang, Y. Zhao, X. G. Yang, F.-F. Li, C. Wang, L. F. Ma, Inorg. Chem. 2019, 58, 15013-15016.

DOI:10.1021/acs.inorgchem.9b02203

46. D. F. Back, G. N. M. De Oliveira, R. A. Burrow, E. E. Castellano, U. Abram, E. S. Lang, Inorg. Chem. 2007, 46, 2356-2358. DOI:10.1021/ic070006q

47. J. Prakasha Reddy, V. R. Pedireddi, Eur. J. Inorg. Chem. 2007, 8, 1150-1158. DOI:10.1002/ejic.200600867

48. M. G. B. Drew, M. R. StJ. Foreman, M. J. Hudson, K. F. Kennedy, Inorg. Chim. Acta 2004, 357, 4102-4112.

DOI:10.1016/j.ica.2004.06.032

49. W.-T. Chen, Y.-P. Xu, Q.-Y. Luo, X.-N. Fang, H.-L. Chen, Z. Anorg. Allg. Chem. 2008, 634, 529-533.
50. W.-T. Chen, J.-S. Huang, X.-N. Fang, Y.-P. Xu, Q.-Y. Luo, Chinese. J. Struct. Chem. 2008, 27, 1270-1274.

51. W.-T. Chen, J.-S. Huang, D.-S. Liu, J.-H. Liu, S.-M. Ying, Chinese. J. Struct. Chem. 2008, 27, 1299-1304.

52. W.-T. Chen. Russ. J. Inorg. Chem. 2009, 54, 1230-1235.

53. W.-T. Chen. J. Mol. Struct. 2011, 992, 102-105.

54. M. A. Katkova, V. A. Ilichev, A. N. Konev, I. I. Pestova, G. K. Fukin, M. N. Bochkarev, Org. Electron. 2009, 10, 623-630. DOI:10.1016/j.orgel.2009.02.020

55. F. Q. Huang, K. Mitchell, J. A. Ibers, Inorg. Chem. 2001, 40, 5123-5126. DOI:10.1021/ic0104353

\section{Povzetek}

$\mathrm{S}$ hidrotermalno sintezo smo pripravili nov Dy-Hg kompleks [Dy(HIA $\left.)_{3}\left(\mathrm{H}_{2} \mathrm{O}\right)_{2}\right]_{2 n} \cdot 2 n \mathrm{HgCl}_{4} \cdot n \mathrm{HgCl}_{5} \cdot n \mathrm{H}_{3} \mathrm{O} \cdot 3 n \mathrm{H}_{2} \mathrm{O}$ (1; HIA = izonikotinska kislina) in ga strukturno okarakterizirali z rentgensko monokristalno analizo. Spojina kristalizira v monoklinski prostorski skupini $C 2 / c$. Kristalna struktura spojine 1 ima eno-dimenzionalno (1- $D$ ) verigo kationa. Fotoluminiscentni eksperiment $\mathrm{v}$ trdnem stanju razkriva, da ima spojina rumen emisijski pas pri $575 \mathrm{~nm}$ ter da ta emisijski pas nastane na podlagi karakterističnega ${ }^{4} F_{9 / 2} \rightarrow{ }^{6} H_{13 / 2}$ prehoda $4 f$ elektronov na Dy ${ }^{3+}$ ionih. Spojina ima CIE kromatične koordinate 0.5168 in $0.4824 \mathrm{v}$ rumenem področju. UV-vidna difuzna refleksija v trdnem razkrije, da ima spojina širok optični pas $3.39 \mathrm{eV}$.

Except when otherwise noted, articles in this journal are published under the terms and conditions of the Creative Commons Attribution 4.0 International License 